\title{
Impact of psychological factors on the health-related quality of life of patients treated for pulmonary arterial hypertension
}

\author{
Laurence Halimi $^{\mathrm{a}, \mathrm{b}, *}$, Grégory Marin ${ }^{\mathrm{c}}$, Nicolas Molinari ${ }^{\mathrm{c}, \mathrm{d}}$, Anne-Sophie Gamez ${ }^{\mathrm{b}}$, \\ Clément Boissin ${ }^{\mathrm{a}, \mathrm{b}}$, Carey M. Suehs ${ }^{\mathrm{b}, \mathrm{c}}$, Isabelle Vachier ${ }^{\mathrm{b}}$, Arnaud Bourdin ${ }^{\mathrm{a}, \mathrm{b}, \mathrm{e}}$

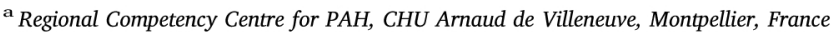 \\ ${ }^{\mathrm{b}}$ Department of Respiratory Diseases, CHU Arnaud de Villeneuve, Montpellier, France \\ ${ }^{\mathrm{c}}$ Department Medical Information, Montpellier University Hospitals, Montpellier, France \\ ${ }^{\mathrm{d}}$ Institut Montpelliérain Alexander Grothendieck, CNRS, University of Montpellier, France \\ e PhyMedExp, University of Montpellier, INSERM U1046, CNRS UMR 9214, Montpellier Hospital, Montpellier, France
}

Keywords:

Pulmonary arterial hypertension

Health-related quality of life

Anxiety-depression

Coping

6-min walk distance

Oxygen desaturation

\begin{abstract}
A B S T R A C T
Objective: Pulmonary arterial hypertension (PAH) is a rare and life-threatening disease well-marked by under diagnosis, delayed diagnosis and atypical treatments. Few data are available on the quality of life (QoL) and psychosocial characteristics of patients with PAH. Our aim is to describe the impact of psychological factors on the health-related quality of life (HRQoL) of treated PAH patients in a cross-sectional study.

Methods: Consecutive patients presenting at our Competency Centre for PAH were recruited. The aetiology, New York Heart Association (NYHA) stage, haemodynamics, 6-min walk distance (6MWD), delta $\mathrm{SPO}_{2}\left(\mathrm{Pulse}_{\text {oxi- }}\right.$ meter oxygen saturation; baseline lowest value during 6-min walk test (6MWT), current treatments and psychological history were recorded. HRQoL, anxiety, depression and coping strategies were explored using selfadministered questionnaires (SF-36, HADS, STAI-Y, CHIP and WCC).

Results: A total of 55 patients were included. The HRQoL of PAH patients was poor with altered results on several scales. Anxiety and depression were high and coping was focused on medical information strategies. Multivariate analysis indicated a positive relationship between 6MWD and the Physical Composite Score for QoL $(\mathrm{p}=0.004)$, as well as a negative relationship between delta $\mathrm{SPO}_{2}$ and the Mental Composite Score $(\mathrm{p}=0.02)$, irrespective of other known prognostic factors (such as haemodynamics at right heart catheterization). Depression and Trait-Anxiety were associated with a lower physical $(\mathrm{p}=0.001)$ and mental $(\mathrm{p}<0.001)$ QoL, respectively.

Conclusions: Psychological factors impact the HRQoL of treated patients. A longitudinal and qualitative study should refine these results.

Trial Registration: Clinical trial N: NCT01380054.
\end{abstract}

\section{Introduction}

Pulmonary arterial hypertension (PAH) is a rare disease characterized by progressive elevation of pulmonary arterial pressure leading to right-side heart failure and was previously thought to occur primarily among women [1]. In the beginning of $\mathrm{PAH}$, symptoms remain vague (fatigue, shortness of breath on exertion, exercise limitations) and patients may consult several doctors before being diagnosed. In 2006, there were approximately $1700 \mathrm{PAH}$ patients in France and between 15 and 50 cases per million individuals worldwide [2]. Thirty years ago, the life-expectancy of a patient with $\mathrm{PAH}$ was only 3 years after diagnosis. Today, treatments have been developed and the physical/ cardiovascular effects of PAH are well documented. Though overall prognosis has improved [3], mortality remains high. At all stages of $\mathrm{PAH}$, patients are faced with a serious medical and psychosocial situation that can have potentially life-altering consequences (interruption of professional activity, sedentary life-style, high risk of morbidity and mortality during pregnancy). Most researchers insist on the need for longitudinal studies [4] and many publications start with the words: "PAH is a devastating or debilitating disease..." [4-7].

In the literature, the terms "health status", "health-related quality of life" and "quality of life" are used interchangeably [8]. For the purposes of this paper, we retain a definition of HRQoL derived from the WHO definition of QoL [9]: HRQol is defined as an individual's perception

\footnotetext{
*Corresponding author at: CHU Arnaud de Villeneuve, 371 avenue du Doyen Gaston Giraud, 34295 Montpellier, Cedex 5, France.

E-mail address: 1-halimi@chu-montpellier.fr (L. Halimi).
} 
concerning his/her own health, integrating impacts related to diseases or treatments on his/her QoL [10]. Due to lack of consensus, many HRQoL questionnaires actually measure self-perceived health status [11].

Current literature on the psychological characteristics and HRQoL of PAH patients is composed of small studies, often targeting specific populations or patient association members [12-14]. This can be linked to difficulties in recruiting patients who have chronic disease, but with a short life-expectancy, resulting in many studies that are cross-sectional and of short duration [15]. In addition, the fact that women are usually overrepresented in PAH studies (from 81 to $88 \%$ of cases) $[4,6,16-19]$ may bias results concerning emotional responses focussed on anxiety, depression or QoL [20]. Depression is nearly always investigated using self-questionnaires sent to the patient's home, whereas these symptoms merit a face to face clinical evaluation [21-23]. Finally, with a few rare exceptions [12,17], most such studies focussing on psychological disorders involve no or few psychologists and/or researchers in psychology. In incident patients, HRQoL is a prognostic marker in PAH [24] and today, international guidelines recommend improving PAH-related QoL and providing psychological management [1]. It is therefore time to focus on studies involving multidisciplinary teams, including professionals in psychology, as well as more representative populations.

The objectives of the PAH and Psychological factors (HyPsy) study were to investigate the impact of psychological factors on HRQoL, the association between HRQOL and the evolution of PAH, as well as the evolution of HRQoL. In this report, we describe the cross-sectional analysis of HRQoL in the HyPsy study population and the psychomedical characteristics of the patients at the time of study inclusion.

\section{Methods}

\subsection{Patients and study design}

The Montpellier Hospital became the Regional Competency Centre for PAH in Languedoc-Roussillon (France) in 2008. Following this, patients rapidly requested socio-psychological help. Taking into account the scarcity of data, at the end of a meeting involving the referent pulmonologist for PAH, a psychologist and the French Association of PAH patients, the decision to implement a prospective study was taken, beginning in May 2011.

Consecutive patients with idiopathic, post-embolic, familial PAH or PAH associated with various diseases were recruited (Groups I and IV of the last ESC/ERS classification [25]). The criteria for the definition of the disease (mean pulmonary arterial pressure (mPAP) $>25 \mathrm{mmHg}$, pulmonary capillary wedge pressure (Pcwp) $<15 \mathrm{mmHg}$, right ventricular pressure (RVP) $>3$ wood units, presence of ventilation-perfusion (V/Q) scan mismatches for group IV) were derived from the recommendations of the 5th World Congress on PAH (Nice, France, March 2013) [26]. The inclusion criteria were: age $18-80$ years; prevalent or incident cases (newly diagnosed, stable for $\geq 3$ months); specific NYHA functional class severity I to IV; not operable; not receiving psychological care in the Competency Centre. The exclusion criteria included: low cardiac output [cardiac index $<2 \mathrm{~L} / \mathrm{min} / \mathrm{m}^{2}$ ]; pre-mortem state; and cognitive impairments.

The anticipated duration of participation was 48 months. The patients were seen every 3 months to assess their clinical and psychological state. Ethics committee approval for the study was granted by the Committee for the Protection of Persons, South-Mediterranean III, (reference number: 2011.04.01). All patients gave their written informed consent to participate in the study.

\subsection{Data collection}

The initial medical assessment was carried out by the clinician responsible for the study. The medical data collected included: NYHA functional class; comorbidities (psychotropic medications); specific treatments for PAH; long term oxygen therapy, 6MWD (at rest and minimal pulse oximeter oxygen saturation $\left(\mathrm{SPO}_{2}\right)$, distance and Borg dyspnoea visual scale score); echocardiography; and haemodynamic parameters recorded at right heart catheterization (RHC). A psychosocio-demographic questionnaire was completed by all patients. Given the current lack of French validated questionnaires for the PAH population, we chose general-population tools (which additionally enabled comparison with other, better-known, serious diseases), validated in French, and which previously demonstrated published utility in PAH populations $[16,17,21]$. All questionnaires were completed in the presence of the project psychologist.

The Medical Outcomes Study 36-item Short Form Heath Survey (SF36), version 1.0 , is a generic HRQoL scale which explores physical, emotional and social health status [27] and is well-validated in French [28]. It evaluates eight dimensions of health: (i) physical functioning; (ii) role limitations due to physical health problems; (iii) bodily pain; (iv) general health; (v) vitality; (vi) social functioning; (vii) role limitations due to emotional problems; and (viii) mental health. The physical composite score (PCS) and mental composite score (MCS), summarize these eight dimensions. The lower the score, the poorer the HRQOL.

Anxiety and depression were studied with the Hospital Anxiety and Depression Scale (HADS) [29] and the State-Trait Anxiety Inventory (STAI-Y) [30], both validated in French [31-34]. The HADS detects anxiety and/or depression, evaluates their severity and avoids confusion with somatic illnesses (non-cases: 0-7; possible cases: 8-10; probable cases: 11-21). The global score was also taken into account: no anxio-depressive disorders: $0-14$; presence of anxio-depressive disorders: 15-42 [35]. The STAI-Y evaluates anxiety and differentiates trait (TA) from state anxiety (SA) (very high anxiety $>65$, high $=56-65$, average $=46-55$, low $=36-45$, very low $\leq 35$ ). TA can be defined as personality disposition, a relatively stable tendency to feel stress. SA can be defined as fear induced temporarily by situations perceived as dangerous.

Coping refers to the thoughts and actions we use to deal with a situation in order to master or tolerate stress. Coping strategies were studied with the Ways of Coping Check List (WCC), which is linked to a stressful event [36] and the Coping with Health Injuries and Problems (CHIP) scale, specific to health-related problems [37]. Both were validated in French $[38,39]$. The CHIP scale was constructed for patients with cancer and revised for patients suffering from other somatic diseases. Normative data for study comparisons are provided in the manual [40]. It includes four sub-scales: 'Distraction' defined as: attempts to think of more agreeable things; 'Instrumental': strategy linked to the search for medical information; 'Emotional': focus on emotional aspects linked to the state of health (anger, frustration, worry, etc.); 'Palliative': alleviates the unpleasant aspects of the situation (taking care of oneself, sleeping, etc.). The WCC identifies, from a stressful situation not linked to the disease (divorce, moving, conflict, etc.), strategies which have been used to confront the situation. It includes three sub-scales for coping (problem-focused, emotion-focused, search for social support).

\subsection{Statistical analysis}

Quantitative variables derived from the descriptive analysis are expressed as means \pm standard deviation and qualitative variables as numbers and percentages. Due to non-normal distributions and a relatively small number of patients in our cohort, we decided to dichotomise the PCS and MCS scores, in order to obtain greater statistical power and a clearer clinical interpretation. Given that pertinent SF-36 cut offs do not currently exist, we chose a statistic, reproducible option: the cut-offs were defined as the PCS and MCS medians (36.92 and 43.46, respectively). Two logistic regression models were then established to model the relationships between psychological and clinical 
variables and the two scores. For more clinical pertinence, the predictive variables were divided between two models, the first containing the psychological parameters and the second the medical parameters. Univariate analyses were carried out and all variables with a $p$ value $<0.15$ were retained for multivariate logistic analyses. For these two analyses, the final models with variables significant at $\mathrm{p}<0.05$ were obtained after a stepwise selection procedure. In order to relate to clinical practice, a complete multivariate model was built to test the relative weights of the psychological and medical groups of data available to clinicians and to help them further consider pertinent criteria associated with HRQoL.

\section{Results}

\subsection{Study population}

A total of 75 potentially eligible subjects were selected. To avoid bias, thirteen patients already receiving psychotherapy by the psychologist responsible for the study were excluded, two refused to participate and five were not eligible due to their inability to read. Thus, a total of 55 consecutive patients were included in the study (mean age: $57.8 \pm 15.3$ years; $64 \%$ female): $14.5 \%$ were involved in a professional activity, $58 \%$ lived with someone and $22 \%$ were newly diagnosed (incident cases) (Table 1). From a medical perspective, the patients included were fairly representative of the population usually described for PAH (1). > 50\% were in functional classes I-II and the

Table 1

Demographic and clinical characteristics of the patients with PAH.

\begin{tabular}{|c|c|}
\hline Characteristics & PAH patients $(\mathrm{N}=55)$ \\
\hline Age (years)* & $57.8 \pm 15.3$ \\
\hline Sex (F), n (\%) & $35(64)$ \\
\hline Professional activity (4 on sick leave), n (\%) & $8(14.5)$ \\
\hline Lower than high school education, $n(\%)$ & $28(51)$ \\
\hline Living with someone, n (\%) & $32(58)$ \\
\hline Patient association members, n (\%) & $13(23)$ \\
\hline $\begin{array}{l}\text { Psychotropic medications (past or present) }{ }^{* *}, \mathrm{n} \\
(\%)^{* * * *}\end{array}$ & $32(58)$ \\
\hline $\begin{array}{l}\text { Among whom patient association members, } \mathrm{n} \\
(\%)\end{array}$ & $10(77)$ \\
\hline Psychiatric monitoring in the past/present, $\mathrm{n}(\%)$ & $11(20) / 1(0.5)$ \\
\hline $\begin{array}{l}\text { Among whom patient association members, } \mathrm{n} \\
(\%)\end{array}$ & $5(39)$ \\
\hline Group I PAH (\%)/CTEPH (IV) & $78.2 / 21.8$ \\
\hline \multicolumn{2}{|l|}{ PAH treatments, n (\%) } \\
\hline No treatment & $1(2)$ \\
\hline Monotherapy & $21(38)$ \\
\hline Bitherapy & $23(42)$ \\
\hline Tritherapy (ERA, IPDE-5, PGI2) & $9(16)$ \\
\hline Calcium channel blockers & $1(2)$ \\
\hline Oxygen, n (\%) & $24(44)$ \\
\hline Co-morbidities, n (\%) & $38(69)$ \\
\hline Incident/prevalent, n (\%) & $12(22) / 43(78)$ \\
\hline NYHA I/II/III/IV, n (\%) & $8(15) / 25(45) / 19(35) / 3(5)$ \\
\hline Cardiac output $(1 / \mathrm{min})=$ & $5.3 \pm 1.9$ \\
\hline mPAP (mmHg) & $46.1 \pm 14.5$ \\
\hline Pcwp (mmHg)* & $9.3 \pm 3.6$ \\
\hline $\mathrm{RAP}(\mathrm{mmHg})$ & $8.0 \pm 4.4$ \\
\hline PVR (Wood's units) ${ }^{*}$ & $10.0 \pm 6.6$ \\
\hline Distance (6MWD) & $382 \pm 33.2$ \\
\hline Min 6MWD $\mathrm{SpO}_{2}(\%)$ & $84.9 \pm 10.6$ \\
\hline Max 6MWD Borg score & $4.8 \pm 2.7$ \\
\hline
\end{tabular}

PAH: pulmonary arterial hypertension; CTEPH: chronic thromboembolic pulmonary hypertension; PAP: pulmonary arterial pressure; Pcwp: pulmonary capillary wedge pressure; RAP: right arterial pressure; PVR: pulmonary vascular resistance; 6MWD: 6-min walk distance.

$*$ Mean \pm SD

** Both antidepressants, benzodiazepines and neuroleptics.

*** Before or/and at inclusion and for 3 months minimum.

"**** Group I ("idiopathic") and IV ("chronic thromboembolic").
Table 2

Quality of life and psychological characteristics of the patients with PAH.

\begin{tabular}{|c|c|}
\hline Characteristics & PAH patients $(\mathrm{N}=55)$ \\
\hline \multicolumn{2}{|l|}{ HADS Anxiety and depression } \\
\hline $\begin{array}{l}\text { General score (disorders/no } \\
\text { disorders) } \mathrm{n}(\%)\end{array}$ & $28(51) / 27(49)$ \\
\hline Non-cases (A/D), n (\%) & $23(42) / 32(58)$ \\
\hline Possible cases (A/D), n (\%) & $20(36) / 14(25)$ \\
\hline Probable cases (A/D), n (\%) & $12(22) / 9(16)$ \\
\hline Anxiety" & $8.7 \pm 4.7$ \\
\hline Depression* & $6.16 \pm 3.9$ \\
\hline STAI-Y State Anxiety* & $48.2 \pm 7.5$ \\
\hline Women/Men & $46.9 \pm 7.3 / 50.4 \pm 7.5$ \\
\hline $\begin{array}{l}\text { Very mild/mild/moderate/severe/ } \\
\text { very severe, } \mathrm{n}(\%)\end{array}$ & $0 / 22(40) / 22(40) / 10(18) / 1(2)$ \\
\hline STAI-Y Trait Anxiety $*$ & $50.5 \pm 14.0$ \\
\hline Women/Men & $49.2 \pm 11.5 / 52.8 \pm 12.8$ \\
\hline $\begin{array}{l}\text { Very mild/mild/moderate/severe/ } \\
\text { very severe, } \mathrm{n}(\%)\end{array}$ & $10(18) / 10(18) / 13(24) / 14(25) / 8(15)$ \\
\hline \multicolumn{2}{|l|}{$\begin{array}{l}\text { CHIP Coping with health injuries and } \\
\text { problems }\end{array}$} \\
\hline CHIP Distraction & $27.3 \pm 6.6$ \\
\hline CHIP Palliative & $26.1 \pm 4.8$ \\
\hline CHIP Information & $30.4 \pm 6.2$ \\
\hline CHIP Emotional & $25.1 \pm 7.5$ \\
\hline \multicolumn{2}{|l|}{ WCC Coping with a stressful event ${ }_{*}$} \\
\hline WCC Problem & $26.3 \pm 5.6$ \\
\hline WCC Emotion & $23.2 \pm 5.8$ \\
\hline WCC Social support & $20.5 \pm 5.5$ \\
\hline \multicolumn{2}{|l|}{ SF-36 Quality of Life $*$} \\
\hline Physical functioning & $46.3 \pm 26.2$ \\
\hline Role-physical & $40.4 \pm 38.6$ \\
\hline Bodily pain & $58.4 \pm 26.1$ \\
\hline General health & $39.8 \pm 18.6$ \\
\hline Vitality & $45.6 \pm 17.8$ \\
\hline Social functioning & $60.9 \pm 25.8$ \\
\hline Role-emotional & $48.4 \pm 42.4$ \\
\hline Mental health & $56.0 \pm 18.6$ \\
\hline PCS & $37.1 \pm 8.03$ \\
\hline MCS & $42.4 \pm 10.9$ \\
\hline
\end{tabular}

${ }^{*}$ Mean \pm SD; PCS: physical composite score; MCS: mental composite score.

mean 6MWD \pm SD was $382 \pm 33 \mathrm{~m}$. The haemodynamic parameters for those patients who were already being treated (58\% receiving bi- or tritherapy) corresponded to severe PAH (pulmonary vascular resistance of $10.0 \pm 6.6$ Wood's units) but with conserved cardiac output (Table 1).

\subsection{HRQoL and psychological aspects}

PAH-related QoL was poor and the mean values for PCS $(37.1 \pm 8.03)$ and MCS $(42.4 \pm 10.9)$ were particularly low. "Bodily pain" (58.4 \pm 26.1$)$ and "Social Functioning" $(60.9 \pm 25.8)$ were the dimensions where patients had the highest scores (Table 2).

The use of the SF-36 enabled us to make comparisons with other severe, disabling and better known diseases, using the SF-36 manual [28]. Compared to cancer or left heart failure, PAH-related QoL was poorer, particularly in: 1- Physical Functioning: Cancer (68.6 \pm 23.5 ), LHF (59.8 \pm 25.8$)$, PAH (46.3 \pm 26.2); 2- General Health: Cancer (50.3 \pm 21.3), LHF (49.8 \pm 19.0), PAH (39.8 \pm 18.6); 3- Emotional Role: Cancer $(67.9 \pm 39.5), \operatorname{LHF}(62.0 \pm 40.8)$, PAH (48.4 \pm 42.4).

Before the onset of PAH and upon inclusion, $58 \%$ of patients had used or still used psychotropic drugs (Table 1). One-fifth (20\%) had followed a psychological or psychiatric plan. As concerns patient associations, our clinical experience is that membership is more likely during the final stages of the disease, and is linked with a higher use of psychological care or psychotropic drugs. In terms of absolute values, our data support this observation ( $77 \%$ vs. $58 \%$ ), but remain insignificant ( $\mathrm{p}=0.20$ ) and underpowered (208 patients would be required to show significativity for this difference). The HADS sub-scales showed 
that $41 \%$ of patients suffered from probable or possible depression and $58 \%$ from probable or possible anxiety (Table 2). The total score indicated that $51 \%$ of PAH patients suffered from an anxio-depressive disorder. The mean values for TA $(50.5 \pm 14.0)$ and SA $(48.1 \pm 7.5)$ were particularly high, especially for men [(SA, women (46.9 \pm 7.3), men $\quad(50.4 \pm 7.5))] ; \quad[(\mathrm{TA}, \quad$ women $\quad(49.2 \pm 11.5)$, men $(52.8 \pm 12.8))]$. More than half $(60 \%)$ of the patients had a moderate to very high SA and $64 \%$ had a moderate to very high TA. In addition, $58 \%$ of individuals had a SA $<$ TA, which according to the authors' recommendations for interpretation suggests that these individuals felt better in their immediate environment (hospital and psychological space).

To cope with stressful events, PAH patients mainly had strategies focussed on problems $(26.3 \pm 5.6)$, similar to French norms $(27.3 \pm 5.8)$ [43]. Regarding strategies used to cope with the disease, they used mainly information coping strategies $(30.4 \pm 6.2)$. The distraction $(27.3 \pm 6.6)$, palliative $(26.1 \pm 4.8)$ and emotional subscales $(25.1 \pm 7.5)$ were high as compared with normative data provided by the CHIP manual [40].

\subsection{Logistic regression}

The following psychological parameters were selected for logistic regression analysis following univariate analysis: TA, HAD depression, HAD total, CHIP D, I, E and WCC scores for predicting the PCS, and SA, TA, HAD anxiety and depression, HAD total, CHIP D, I and E scores for predicting the MCS (Table 3). Logistic regression analysis revealed a significant negative relationship between depression and PCS: an increase of 1 in the depression score brought about a $32 \%$ decrease ( $1 /$ $0.76=1.32$ ) in the odds of having a high PCS, that is to say greater than the median [adjusted Odds ratio (aOR) $=0.76$, 95\%CI: 0.64-0.90; $\mathrm{p}=0.001]$. A patient with a high depression score had a lower probability of having a high physical QoL. Similarly, an increase of 1 in the TA score led to a $16 \%$ decrease in the odds of having a high MCS [aOR $=0.86,95 \% \mathrm{CI}: 0.80-0.93 ; \mathrm{p}<0.001]$. The higher the anxiety score, the lower the odds of the patient having a high mental QoL (Table 3).

Regarding clinical parameters, variables with $\mathrm{p}$ values $<0.15$ at univariate analysis were selected for the logistic regression analysis: the $6 \mathrm{MWD}$ and NYHA class for predicting the PCS; cardiac output, 6MWD, NYHA class and delta $\mathrm{SpO}_{2}>4 \%$ for predicting the MCS (Table 4). Multivariate analysis showed a significant positive relationship between 6MWD and PCS [aOR $=1.08$, 95\%CI: 1.03-1.14; $\mathrm{p}=0.004]$ (a
Table 4

Medical parameters: univariate and multivariate analyses.

\begin{tabular}{|c|c|c|c|c|c|c|}
\hline \multirow{2}{*}{$\begin{array}{l}\text { QoL } \\
\text { Univariate analysis }\end{array}$} & \multicolumn{2}{|c|}{ PCS determinants } & \multicolumn{4}{|c|}{ MCS determinants } \\
\hline & cOR & $95 \% \mathrm{CI}$ & $\mathrm{p}$ & cOR & $95 \% \mathrm{CI}$ & $\mathrm{p}$ \\
\hline Treaments PAH, n & 0.89 & [0.42-1.85] & 0.74 & 0.74 & [0.35-1.56] & 0.43 \\
\hline mPAP & 1.00 & [0.96-1.04] & 1.00 & 0.98 & [0.95-1.02] & 0.42 \\
\hline Pcwp & 0.95 & [0.81-1.12] & 0.57 & 0.88 & [0.74-1.05] & 0.16 \\
\hline Cardiac output & 1.22 & [0.89-1.68] & 0.23 & 0.77 & [0.55-1.08] & $0.13^{*}$ \\
\hline OD & 0.89 & [0.74-1.06] & 0.20 & 0.97 & [0.82-1.13] & 0.66 \\
\hline $\begin{array}{l}\text { Distance } \\
\qquad(6 \mathrm{MWD})^{* * *}\end{array}$ & 1.08 & [1.03-1.15] & $0.004^{*}$ & 1.05 & [1.00-1.10] & 0.03 \\
\hline NYHA & & & 0.048 & & & 0.19 \\
\hline II vs I & 0.59 & [0.10-3.57] & 0.57 & 0.13 & [0.01-1.23] & 0.08 \\
\hline III vs I & 0.12 & {$[0.02-0.79]$} & $0.03^{*}$ & 0.08 & {$[0.01-0.83]$} & $0.03^{*}$ \\
\hline IV vs I & 0.17 & [0.01-2.98] & 0.22 & 0.07 & [0.00-1.73] & $0.10^{*}$ \\
\hline Delta $\mathrm{SPO}_{2}$ & 0.92 & [0.23-3.66] & 0.91 & 0.19 & {$[0.04-0.86]$} & $0.03^{*}$ \\
\hline Multivariate & $\mathrm{aOR}$ & $95 \% \mathrm{CI}$ & $\mathrm{p}$ & $\mathrm{aOR}$ & $95 \% \mathrm{CI}$ & $\mathrm{p}$ \\
\hline $\begin{array}{l}\text { Distance } \\
\qquad(6 \mathrm{MWD})^{*}\end{array}$ & 1.08 & [1.03-1.15] & 0.004 & & & \\
\hline Delta $\mathrm{SPO}_{2}$ & & & & 0.18 & {$[0.04-0.81]$} & $<0.02$ \\
\hline
\end{tabular}

cOR: crude Odds-ratio; aOR: adjusted Odds-ratio; 6MWD: 6-min walk distance; PCS: physical composite score; MCS: mental composite score; CI: confidence intervals.

* Included in the multivariate analyses.

** Units $=10 \mathrm{~m}$

***: $\geq 4 \%$ vs $<4 \%$.

$10 \mathrm{~m}$ increase in the walking distance led to a $8.4 \%$ increase in the odds of having a high PCS) and a significant negative relationship between delta $\mathrm{SpO}_{2} \geq 4 \%$ and MCS: the odds of having a high MCS were almost 6 times lower in patients with a Delta $\mathrm{SpO} 2$ (variation of $\mathrm{SPO}_{2}$ during $6 \mathrm{MWT}$ ) $\geq 4 \%$ [aOR $=0.18,95 \% \mathrm{CI}: 0.04-0.81 ; \mathrm{p}=0.02$ ] (Table 4). In other words, a patient with a low blood oxygen concentration had a lower probability of having a high MCS.

In order to relate all these multivariate results to clinical parameters, HAD depression and 6MWD values were pooled in the same multivariate model and both "tended" to remain related to PCS ( [aOR $=0.85,95 \% \mathrm{CI}: 0.71-1.01 ; \mathrm{p}=0.07]$ and $[\mathrm{aOR}=1.01,95 \% \mathrm{CI}$ : $1.00-1.01 ; \mathrm{p}=0.06])$. Moreover, the TA score and Delta Sp02 $\geq 4 \%$ were pooled together and remained significantly related to MCS ( $[\mathrm{aOR}=0.81,95 \% \mathrm{CI}: 0.69-0.94 ; \mathrm{p}=0.01]$ and $\quad[\mathrm{aOR}=0.02$, 95\% CI: $<0.01-0.59 ; \mathrm{p}=0.02])$.

Table 3

Psychological parameters: univariate and multivariate analyses.

\begin{tabular}{|c|c|c|c|c|c|c|}
\hline \multirow{2}{*}{$\begin{array}{l}\text { QoL } \\
\text { Univariate analysis }\end{array}$} & \multicolumn{3}{|c|}{ PCS determinants } & \multicolumn{3}{|c|}{ MCS determinants } \\
\hline & $\mathrm{cOR}$ & $95 \% \mathrm{CI}$ & $\mathrm{p}$ & cOR & $95 \% \mathrm{CI}$ & $\mathrm{p}$ \\
\hline STATE anxiety & 0.95 & [0.88-1.02] & 0.172 & 0.86 & [0.77-0.94] & 0.0009 \\
\hline TRAIT anxiety & 0.95 & [0.91-0.99] & $0.021 *$ & 0.86 & [0.79-0.92] & $<0.0001$ \\
\hline HAD anxiety & 0.93 & [0.83-1.05] & 0.243 & 0.74 & {$[0.63-0.88]$} & $0.0003^{*}$ \\
\hline HAD depression & 0.77 & {$[0.66-0.91]$} & 0.002 & 0.66 & [0.53-0.81] & $<0.0001$ \\
\hline HAD total & 0.91 & [0.84-0.98] & $0.017^{*}$ & 0.78 & [0.69-0.88] & $<0.0001$ \\
\hline CHIP distraction & 1.05 & [1.01-1.10] & $0.010^{*}$ & 1.04 & [1.00-1.08] & $0.051^{*}$ \\
\hline CHIP information & 1.03 & [0.99-1.08] & 0.123 & 1.05 & [1.00-1.09] & 0.035 \\
\hline CHIP palliative & 0.98 & [0.94-1.02] & 0.436 & 0.99 & [0.95-1.03] & 0.625 \\
\hline CHIP emotional & 0.97 & [0.93-1.01] & $0.137^{*}$ & 0.93 & [0.89-0.97] & 0.002 \\
\hline WCC problem & 1.10 & [0.99-1.23] & 0.069 & 1.00 & [0.95-1.16] & 0.34 \\
\hline WCC emotion & 0.97 & [0.89-1.07] & 0.628 & 0.96 & [0.87-1.05] & 0.36 \\
\hline WCC support & 1.00 & [0.91-1.11] & 0.887 & 0.95 & [0.85-1.05] & 0.28 \\
\hline Multivariate & aOR & $95 \% \mathrm{CI}$ & $\mathrm{p}$ & $\mathrm{aOR}$ & $95 \% \mathrm{CI}$ & $\mathrm{p}$ \\
\hline HAD depression & 0.76 & [0.64-0.090] & 0.001 & & & \\
\hline Trait anxiety & & & & 0.86 & [0.80-0.093] & $<0.001$ \\
\hline
\end{tabular}

cOR: crude Odds-ratio; aOR: adjusted Odds-ratio; PCS: physical composite score; MCS: mental composite score; CI: confidence intervals.

${ }^{*}$ Included in the multivariate analyses. 


\section{Discussion}

We juxtaposed HRQoL with disease descriptors (such as cardiac output or 6MWD) and to data related to the patient her/himself (such as psychological factors and personality traits) [1]. PAH patients have a poor physical HRQoL, with a large majority suffering from anxio-depressive problems and using more problem-focused strategies to cope with daily stress and more information strategies to cope with the disease. In our study, logistic regression analyses showed that patients who had severe depression or a high trait anxiety had a lower PCS and MCS, respectively, which persisted when taking into account clinical variables. Conversely, patients with a longer 6MWD had a better physical HRQoL, whereas those with higher oxygen desaturation had a worse mental HRQoL.

\subsection{HRQOL}

In the literature, the PAH-related QoL of women was compared with the norms for the general female population and indicated physical and emotional limitations [4]. In our study, compared to HRQoL for cancer or left heart failure, PAH-related QoL was poor. The PAH patients enrolled were also younger (Cancer: 64.7 years; LHF: 69.7 years; PAH 57.8 years) [28]. Notably, shortness of breath is the most disabling symptom in PAH as it is in LHF. Bodily Pain was a dimension where our patients had a higher score. Thus, their HRQoL did not appear to be altered by physical suffering, despite receiving certain treatments with potentially painful side-effects (jaw pain, headache, nausea, diarrhoea, leg cramps, as well as pain and infection at the intra venous site).

\subsection{Anxiety and depression}

Over half of our PAH patients suffered from an anxio-depressive disorder. McCollister et al. showed that $15 \%$ of patients had serious depression and $40 \%$ had mild to moderate symptoms [6]. A second study on patient association members demonstrated that $33 \%$ suffered from mental disorders, which increased with functional class severity [12]. Such patient association member studies are suggested to underestimate the true levels of anxio-depressive disorders in the $\mathrm{PAH}$ population [14]; however, our results, though insignificant, do not support such a pattern. Shafazand et al. further reported that patients on prostacyclin were less anxious and depressed than others [4]; the duration of treatment with prostacyclin (an unstable pharmacological product associated with multiple and potentially severe side effects) and the treatment of psychopathological disorders was not reported. Harzheim et al. showed that $22.8 \%$ of patients suffered from moderate/ severe depression or anxiety disorders [41]. Anxiety and depression were not associated with survival. It is possible that depression and anxiety may subside over time because of survival, improvement or disease stability. In our study, less than half of the patients were in the worst NYHA classes (III-IV).

As concerns the STAI-Y questionnaire, PAH patients appeared to have more psychological disorders than other patient groups [34]. $\mathrm{PAH}$ progression may lead to treatment changes or intensification at a rhythm exceeding that required for patient adaptation. In cancer, progression has been well described and anxiety is strong because patients can represent certain aspects of the future (hair loss, vomiting, etc.). In contrast, in PAH, patients suffer from not knowing what is going to happen to them, which likely increases their fear [13] (which is potentially further amplified by a delay in diagnosis of three years or more) [2]. Suddenly, patients are faced with this poorly known diagnosis hallmarked by complex physiopathology and medications that are potentially unknown not only for them, but also for their GP and/or pharmacists. All these aspects have the potential to elicit fear and anxiety. Unexpectedly at inclusion, PAH patients included in the present study did not have a higher state anxiety (SA) than usual (TA), despite having to wait for assessments required for prognosis, such as right heart catheterization or cardiac MRI (Magnetic Resonance Imaging). We hypothesize therefore that they are reassured by the multidisciplinary management tailored for them in a competency centre, not only because the personnel had knowledge of their disease, but also probably because they met other patients suffering from the same disease. Our current understanding is that feeling you are a "unique case" is likely to be a strong source of anxiety. Men with PAH appeared to be more anxious than women suffering from PAH. It is possible that this original result is due to the nature of our sample: in our study, females represented $64 \%$ of the study population, while in the literature, from $81 \%$ to $88 \%$ of patients are female $[4,6,16-19]$. PAH can lead to severe handicap and disability (job loss and lack of autonomy that restricts daily life activities to the point where basic tasks, like showering, become impossible, etc.). Finding a place and sense in life at home might be difficult and anxiogenic for most disabled patients.

Unsurprisingly, anxiety was related to MCS and one could have expected the same for depression, but the latter was mainly associated with PCS. Depression symptoms can include low mood but also energy changes and psychomotor retardation. In a previous study, the poorer a patient's Physical Functioning is, the greater the level of depression [21].This result may help explain the 6MWD described below, and especially why patients might refuse this assessment.

\subsection{Coping}

In our study, to cope with stressful life events and with the disease, PAH patients had strategies primarily focussed on problem and information coping strategies (respectively), indicating a strong tendency to search for a means of controlling the situation. It appears that PAH patients implement strategies aimed at resolving problems, considering their efforts as a necessity given the situation, while more day to day issues become meaningless. In our clinical experience, many patients state that since being diagnosed with $\mathrm{PAH}$, "nothing else is a serious problem".

Compared to other diseases [37], PAH patients used more distractive and palliative strategies aimed at avoiding becoming preoccupied with their health problem and alleviating the undesirable nature of the situation. In one study, 54\% of PAH patients wanted more medical information than what they had been provided with [23]. These facts do not seem contradictory to us. From feed-back based on our clinical experience and from all semi-directed interviews conducted during the protocol, we observed that the patients mostly wanted medical information at the time of diagnosis and when starting long term continuous intravenous treatment. At other times, they did not particularly want medical information.

Coping focussed on emotion is usually linked to a poor HRQoL and, as a result, is associated with symptoms of depression and anxiety [42]. However, no single strategy is effective on its own, regardless of individual characteristics, and cannot change the problem to be resolved, notably the possibility of controlling the situation [36,43]. Insofar as coping affects decisions and QoL, it is nevertheless important to know whether the coping strategy involved is appropriate over the short and long-term.

\subsection{Medical parameters}

Logistic regression analysis showed that the longer the 6MWD the better the PCS, which is expected and in line with a previous study that showed a correlation between PCS, MCS and 6MWD [16]. In contrast, we also have an original observation regarding oxygen desaturation: the greater the oxygen desaturation, the lower the probability of the patient having a high mental HRQoL, independent of disease severity (haemodynamics, functional class). Logistic regression analysis also showed that patients with psychopathological disorders had a lower probability of having a high PCS and MCS compared to other patients. It also appears that patients with a longer 6MWD had less depression and 
a lower NYHA functional class.

These results provoke several thoughts regarding the management of these patients. In $\mathrm{PAH}$, breathlessness first appears during walking that requires a certain amount of effort (e.g. walking upslope), and then progressively appears for other activities that require less and less effort (such as getting dressed, or taking a shower). Eventually, leaving the house becomes difficult, and even the resting state is affected. Psychological problems and social isolation can further complicate physical disability. Dyspnoea on exertion is the primary symptom of $\mathrm{PAH}$, and the 6MWT (as for right heart catheterization) is considered as a main evaluation criteria when evaluating treatments [44]. Our results indicate that every $10 \mathrm{~m}$ increase in the 6-min walking test increases the probability of a high PCS. The latter is of extreme importance because, when monitoring patients, $\mathrm{PAH}$ improvement in association with a given treatment is decided according to a minimal important difference (MID) of approximately $33 \mathrm{~m}$ for the 6MWT [45]. In clinical trials, this same criterion is used to evaluate new treatment responses. Furthermore, $10 \mathrm{~m}$ represents at-home autonomy in the daily life of many patients. In conclusion, the $6 \mathrm{MWD}$ is a robust survival prognostic marker in PAH. It depicts a level of disability impacting QoL and new interventions such as rehabilitation are currently tested with the aim of improving QoL through the improvement of shortness of breath on exertion [46].

In our clinical experience, patients often refuse to take the 6MWT, arguing that they find it impossible to walk on that day, with various anxiety-type excuses (weather, fatigue, insomnia the previous night, etc.). The 6 min walking tests are often missing data in the literature [1]. These reactional anxiety-type excuses usually hide depression, which needs to be studied. Recently, physical activity was associated with fatigue and HRQoL [47]. Conversely, some patients were reported to turn up prepared (i.e. they trained at home for several days before the exam). This test is the only one where they can be active, with understandable medical results considered to be a personal performance. Refusal to perform this test or training to walk may be a reflection of the disease, but may also reflect some level of depression, denial, or of a particular way of facing up to the disease. It is important to remember at this point that depression associates with PCS.

A decrease in oxygen saturation interferes with MCS, and this criterion has rarely been studied to date. Decreased oxygen saturation is known to cause fatigue, decrease QoL, and interfere with behavioral changes, cognitive deficits and psychological difficulties like anxiety and depression [48]. Measuring arterial oxygen saturation is simple: it can also be performed at home, which can for some patients lead to a "disproportionate" anxiety-based dependency on this tool and to a limitation of movement when poor measurements are found. The high prevalence of patients receiving oxygen therapy in our study should be noted (44\%), while no patient suffered from a chronic respiratory disease or a veno-occlusive disease. Oxygen use in PAH is not indicated for all patients and is of non-evident efficacy [1]. The desaturation effect on MCS was not really expected and merits further study for exploring: (i) whether or not oxygen supplementation or other therapeutic interventions would first correct symptoms and then improve the subsequent MCS; (ii) whether or not oxygen deprivation during exercise is a cause or a consequence of a poor mental HRQoL.

\subsection{Strengths and limitations}

There was a relatively small number of patients in our cohort, which could lead to low statistical power, and this limitation has been taken into account in our statistical analysis plan. We aimed at helping clinicians weigh their decisions based on validated medical and psychological criteria associated with QoL. Since PAH is an uncommon disease, the small sample size is understandable. However, this study is strengthened by the multidisciplinary clinical and theoretical approach used, plus the fact that our data well represent both sexes and patients who are members of a patient association as well as those who are not.

\section{Conclusion}

PAH patients have a poor physical HRQol, with a large majority suffering from anxio-depressive problems and using more problem-focused strategies to cope with daily stress and more information strategies to cope with the disease. A decrease in oxygen saturation interferes with the MCS. Patients with a longer 6MWD had less depression and a lower NYHA functional class.

\section{Conflicts of interest and source of funding}

This study was supported by an unrestricted grant from GSK.

\section{References}

[1] N. Galiè, M. Humbert, J.-L. Vachiery, S. Gibbs, I. Lang, A. Torbicki, G. Simonneau, A. Peacock, A. Vonk Noordegraaf, M. Beghetti, A. Ghofrani, M.A. Gomez Sanchez, G. Hansmann, W. Klepetko, P. Lancellotti, M. Matucci, T. McDonagh, L.A. Pierard, P.T. Trindade, M. Zompatori, M. Hoeper, 2015 ESC/ERS guidelines for the diagnosis and treatment of pulmonary hypertension: The joint task force for the diagnosis and treatment of pulmonary hypertension of the european society of cardiology (esc) and the european respiratory society (ers): endorsed by: association for european paediatric and congenital cardiology (aepc), international society for heart and lung transplantation (ISHLT), Eur. Respir. J. 46 (2015) 903-975, http:// dx.doi.org/10.1183/13993003.01032-2015.

[2] M. Humbert, O. Sitbon, A. Chaouat, M. Bertocchi, G. Habib, V. Gressin, A. Yaici, E. Weitzenblum, J.-F. Cordier, F. Chabot, C. Dromer, C. Pison, M. Reynaud-Gaubert, A. Haloun, M. Laurent, E. Hachulla, G. Simonneau, Pulmonary arterial hypertension in France: results from a national registry, Am. J. Respir. Crit. Care Med. 173 (2006) 1023-1030, http://dx.doi.org/10.1164/rccm.200510-16680C.

[3] M. Humbert, E.M.T. Lau, D. Montani, X. Jaïs, O. Sitbon, G. Simonneau, Advances in therapeutic interventions for patients with pulmonary arterial hypertension, Circulation 130 (2014) 2189-2208, http://dx.doi.org/10.1161/ CIRCULATIONAHA.114.006974.

[4] S. Shafazand, M.K. Goldstein, R.L. Doyle, M.A. Hlatky, M.K. Gould, Health-related quality of life in patients with pulmonary arterial hypertension, Chest 126 (2004) 1452-1459, http://dx.doi.org/10.1378/chest.126.5.1452.

[5] L.A. Matura, D.L. Carroll, Human responses to pulmonary arterial hypertension: review of the literature, J. Cardiovasc. Nurs. 25 (2010) 420-427, http://dx.doi.org/ 10.1097/JCN.0b013e3181d25458.

[6] D.H. McCollister, M. Beutz, V. McLaughlin, J. Rumsfeld, F.A. Masoudi, M. Tripputi, T. Yaeger, P. Weintraub, D.B. Badesch, Depressive symptoms in pulmonary arterial hypertension: prevalence and association with functional status, Psychosomatics 51 (2010) 339-339.e8, http://dx.doi.org/10.1176/appi.psy.51.4.339.

[7] L. Guillevin, I. Armstrong, R. Aldrighetti, L.S. Howard, H. Ryftenius, A. Fischer, S. Lombardi, S. Studer, P. Ferrari, Understanding the impact of pulmonary arterial hypertension on patients' and carers' lives, Eur. Respir. Rev. Off. J. Eur. Respir. Soc. 22 (2013) 535-542, http://dx.doi.org/10.1183/09059180.00005713.

[8] M. Karimi, J. Brazier, Health, health-related quality of life, and quality of life: what is the difference? PharmacoEconomics 34 (2016) 645-649, http://dx.doi.org/10. 1007/s40273-016-0389-9.

[9] The World Health Organization quality of life assessment, (WHOQOL): position paper from the World Health Organization, Soc. Sci. Med. 41 (1995) 1403-1409, http://dx.doi.org/10.1016/0277-9536(95)00112-K.

[10] Health-Related Quality of Life (HRQL), (n.d.). http://qol.thoracic.org/sections/keyconcepts/health-related-quality-of-life.html (accessed September 18, 2017).

[11] J.E. Ware, C.D. Sherbourne, The MOS 36-item short-form health survey (SF-36). I. Conceptual framework and item selection, Med. Care 30 (1992) 473-483.

[12] B. Löwe, K. Gräfe, C. Ufer, K. Kroenke, E. Grünig, W. Herzog, M.M. Borst, Anxiety and depression in patients with pulmonary hypertension, Psychosom. Med. 66 (2004) 831-836, http://dx.doi.org/10.1097/01.psy.0000145593.37594.39.

[13] M.P. Flattery, J.M. Pinson, L. Savage, J. Salyer, Living with pulmonary artery hypertension: patients' experiences, Heart Lung J. Crit. Care. 34 (2005) 99-107, http://dx.doi.org/10.1016/j.hrtlng.2004.06.010.

[14] J.M. Wryobeck, G. Lippo, V. McLaughlin, M. Riba, M. Rubenfire, Psychosocial aspects of pulmonary hypertension: a review, Psychosomatics 48 (2007) 467-475, http://dx.doi.org/10.1176/appi.psy.48.6.467.

[15] R. Carroll, J. Antigua, D. Taichman, H. Palevsky, P. Forfia, S. Kawut, S.D. Halpern, Motivations of patients with pulmonary arterial hypertension to participate in randomized clinical trials, Clin. Trials Lond. Engl. 9 (2012) 348-357, http://dx.doi. org/10.1177/1740774512438981.

[16] D.B. Taichman, J. Shin, L. Hud, C. Archer-Chicko, S. Kaplan, J.S. Sager, R. Gallop, J. Christie, J. Hansen-Flaschen, H. Palevsky, Health-related quality of life in patients with pulmonary arterial hypertension, Respir. Res. 6 (2005) 92, , http://dx. doi.org/10.1186/1465-9921-6-92.

[17] J. White, R.O. Hopkins, E.W. Glissmeyer, N. Kitterman, C.G. Elliott, Cognitive, emotional, and quality of life outcomes in patients with pulmonary arterial hypertension, Respir. Res. 7 (2006) 55, , http://dx.doi.org/10.1186/1465-9921-7-55.

[18] O. Batal, O.F. Khatib, N. Bair, L.S. Aboussouan, O.A. Minai, Sleep quality, depression, and quality of life in patients with pulmonary hypertension, Lung 189 (2011) 141-149, http://dx.doi.org/10.1007/s00408-010-9277-9. 
[19] K.M. Swetz, T.D. Shanafelt, L.B. Drozdowicz, J.A. Sloan, P.J. Novotny, L.A. Durst, R.P. Frantz, M.D. McGoon, Symptom burden, quality of life, and attitudes toward palliative care in patients with pulmonary arterial hypertension: results from a cross-sectional patient survey, J. Heart Lung Transplant. Off. Publ. Int. Soc. Heart Transplant. 31 (2012) 1102-1108, http://dx.doi.org/10.1016/j.healun.2012.08. 010.

[20] U. Hess, S. Senécal, G. Kirouac, P. Herrera, P. Philippot, R.E. Kleck, Emotional expressivity in men and women: stereotypes and self-perceptions, Cognit. Emot. 14 (2000) 609-642, http://dx.doi.org/10.1080/02699930050117648.

[21] K.J. Looper, A. Pierre, D.M. Dunkley, J.J. Sigal, D. Langleben, Depressive symptoms in relation to physical functioning in pulmonary hypertension, J. Psychosom. Res. 66 (2009) 221-225, http://dx.doi.org/10.1016/j.jpsychores.2008.09.014.

[22] M. Rubenfire, G. Lippo, B.D. Bodini, F. Blasi, L. Allegra, E. Bossone, Evaluating health-related quality of life, work ability, and disability in pulmonary arterial hypertension: an unmet need, Chest 136 (2009) 597-603, http://dx.doi.org/10. 1378/chest.08-1260.

[23] B. Ivarsson, B. Ekmehag, R. Hesselstrand, G. Rådegran, T. Sjöberg, Perceptions of received information, social support, and coping in patients with pulmonary arterial hypertension or chronic thromboembolic pulmonary hypertension, Clin. Med. Insights Circ. Respir. Pulm. Med. 8 (2014) 21-28, http://dx.doi.org/10.4137/ CCRPM.S18586.

[24] C.J.C.S. Fernandes, B.C.S. Martins, C.V.P. Jardim, R.M. Ciconelli, L.K. Morinaga, A.P. Breda, S. Hoette, R. Souza, Quality of life as a prognostic marker in pulmonary arterial hypertension, Health Qual. Life Outcomes 12 (2014) 130, , http://dx.doi. $\operatorname{org} / 10.1186 / s 12955-014-0130-3$

[25] N. Galiè, M. Humbert, J.-L. Vachiery, S. Gibbs, I. Lang, A. Torbicki, G. Simonneau, A. Peacock, A. Vonk Noordegraaf, M. Beghetti, A. Ghofrani, M.A. Gomez Sanchez, G. Hansmann, W. Klepetko, P. Lancellotti, M. Matucci, T. McDonagh, L.A. Pierard P.T. Trindade, M. Zompatori, M. Hoeper, 2015 ESC/ERS guidelines for the diagnosis and treatment of pulmonary hypertension: the joint task force for the diagnosis and treatment of pulmonary hypertension of the european society of cardiology (esc) and the european respiratory society (ers): endorsed by: association for european paediatric and congenital cardiology (aepc), international society for heart and lung transplantation (ISHLT), Eur. Respir. J. 46 (2015) 903-975, http:// dx.doi.org/10.1183/13993003.01032-2015.

[26] G. Simonneau, M.A. Gatzoulis, I. Adatia, D. Celermajer, C. Denton, A. Ghofrani, M.A. Gomez Sanchez, R. Krishna Kumar, M. Landzberg, R.F. Machado, H. Olschewski, I.M. Robbins, R. Souza, Updated clinical classification of pulmonary hypertension, J. Am. Coll. Cardiol. 62 (2013) D34-41, http://dx.doi.org/10.1016/j. jacc.2013.10.029.

[27] C.A. McHorney, J.E. Ware, A.E. Raczek, The MOS 36-item short-form health survey (SF-36): II. Psychometric and clinical tests of validity in measuring physical and mental health constructs, Med. Care 31 (1993) 247-263.

[28] A. Leplège, E. Ecosse, A. Verdier, T.V. Perneger, The French SF-36 health survey: translation, cultural adaptation and preliminary psychometric evaluation, J. Clin. Epidemiol. 51 (1998) 1013-1023.

[29] A.S. Zigmond, R.P. Snaith, The hospital anxiety and depression scale, Acta Psychiatr. Scand, 67 (1983) 361-370.

[30] C.D. Spielberger, R.L. Gorsuch, R. Lushene, P.R. Vagg, G.A. Jacobs, Manual for the State-Trait Anxiety Inventory, (1983).

[31] J.P. Lepine, M. Godchau, P. Brun, Anxiety and depression in inpatients, Lancet Lond. Engl. 2 (1985) 1425-1426.

[32] J.P. Lépine, M. Godchau, P. Brun, T. Lempérière, Evaluation of anxiety and depression among patients hospitalized on an internal medicine service, Ann. Med.
Psychol. (Paris) 143 (1985) 175-189.

[33] D. Razavi, N. Delvaux, V. Farvacques, E. Robaye, Validation de la version française du HADS dans une population de patients cancéreux hospitalisés, Rev. Psychol. Appliquée. 39 (1989) 295-307.

[34] C. Spielberger, M. Bruchon-Schweitzer, I. Paulhan, State-Trait anxiety inventory, Y format, French translation (Inventaire d'anxiété état-trait. forme y, adaptation française), Paris Édition Cent, Psychol. Appliquée. 68 (1993).

[35] T. Ibbotson, P. Maguire, P. Selby, T. Priestman, L. Wallace, Screening for anxiety and depression in cancer patients: the effects of disease and treatment, Eur. J. Cancer Oxf. Engl. 1990 (30A) (1994) 37-40.

[36] R.S. Lazarus, S. Folkman, Stress, Appraisal, and Coping, Springer, New York 1999http://www.dawsonera.com/depp/reader/protected/external/AbstractView/ S9780826141927 (accessed September 18, 2017).

[37] N.S. Endler, J.D.A. Parker, L.J. Summerfeldt, Coping with health problems: developing a reliable and valid multidimensional measure, Psychol. Assess. 10 (1998) 195-205, http://dx.doi.org/10.1037/1040-3590.10.3.195.

[38] S. Montel, C. Bungener, Validation of CHIP (a coping questionnaire) in French patients with neurological disorders, Rev. Neurol. (Paris) 166 (2010) 54-60, http:// dx.doi.org/10.1016/j.neurol.2009.05.004.

[39] M. Bruchon-Schweitzer, F. Cousson, B. Quintard, J. Nuissier, N. Rascle, French adaptation of the ways of coping checklist, Percept. Mot. Skills 83 (1996) 104-106, http://dx.doi.org/10.2466/pms.1996.83.1.104.

[40] N.S. Endler, J.D. Parker, Coping with Health Injuries and Problems (CHIP): Manual, Multi-Health Systems, 2000.

[41] D. Harzheim, H. Klose, F.P. Pinado, N. Ehlken, C. Nagel, C. Fischer, A. Ghofrani, S. Rosenkranz, H.-J. Seyfarth, M. Halank, E. Mayer, E. Grünig, S. Guth, Anxiety and depression disorders in patients with pulmonary arterial hypertension and chronic thromboembolic pulmonary hypertension, Respir. Res. 14 (2013) 104, http://dx. doi.org/10.1186/1465-9921-14-104.

[42] L.J. Graven, J.S. Grant, Coping and health-related quality of life in individuals with heart failure: an integrative review, Heart Lung J. Crit. Care. 42 (2013) 183-194, http://dx.doi.org/10.1016/j.hrtlng.2012.12.002.

[43] R.D. Nipp, A. El-Jawahri, J.N. Fishbein, J. Eusebio, J.M. Stagl, E.R. Gallagher, E.R. Park, V.A. Jackson, W.F. Pirl, J.A. Greer, J.S. Temel, The relationship between coping strategies, quality of life, and mood in patients with incurable cancer, Cancer 122 (2016) 2110-2116, http://dx.doi.org/10.1002/cncr.30025.

[44] D.B. Badesch, S.H. Abman, G.S. Ahearn, R.J. Barst, D.C. McCrory, G. Simonneau, V.V. McLaughlin, American College of Chest Physicians, medical therapy for pulmonary arterial hypertension: ACCP evidence-based clinical practice guidelines, Chest 126 (2004) 35S-62S, http://dx.doi.org/10.1378/chest.126.1_suppl.35S.

[45] S.C. Mathai, M.A. Puhan, D. Lam, R.A. Wise, The minimal important difference in the 6-minute walk test for patients with pulmonary arterial hypertension, Am. J. Respir. Crit. Care Med. 186 (2012) 428-433, http://dx.doi.org/10.1164/rccm. 201203-04800C.

[46] N.R. Morris, F.D. Kermeen, A.E. Holland, Exercise-based rehabilitation programmes for pulmonary hypertension, Cochrane Database Syst. Rev. 1 (2017) CD011285, , http://dx.doi.org/10.1002/14651858.CD011285.pub2.

[47] L.A. Matura, H. Shou, J.S. Fritz, K.A. Smith, A. Vaidya, D. Pinder, C. Archer-Chicko, D. Dubow, H.I. Palevsky, M.S. Sommers, S.M. Kawut, Physical activity and symptoms in pulmonary arterial hypertension, Chest 150 (2016) 46-56, http://dx. doi. org $/ 10.1016 /$ j.chest.2016.02.633.

[48] E. Kozora, C. Emery, R.M. Kaplan, F.S. Wamboldt, L. Zhang, B.J. Make, Cognitive and psychological issues in emphysema, Proc. Am. Thorac. Soc. 5 (2008) 556-560, http://dx.doi.org/10.1513/pats.200708-123ET. 